\title{
Big DATA \& Business INTELLIGENCE In Government Office BuILDings
}

\author{
Ain Farhana Jamaludin* \\ Department of Real Estate, Faculty of Built Environment and Surveying \\ University Technology Malaysia, Johor Bahru \\ Malaysia \\ a.farhana19@yahoo.com

\section{Muhammad Najib Razali} \\ Department of Real Estate, Faculty of Built Environment and Surveying \\ University Technology Malaysia, Johor Bahru \\ Malaysia \\ mnajibmr@utm.my
}

\section{Rohaya Abdul Jalil}

Department of Real Estate, Faculty of Built Environment and Surveying University Technology Malaysia, Johor Bahru

Malaysia

rohaya@utm.my

\section{Siti Hajar Othman}

School of Computing, Faculty of Engineering University Technology Malaysia, Johor Bahru

Malaysia

hajar@utm.my

\section{Yasmin Mohd Adnan}

Faculty of Built Environment and Surveying

University Malaya, Kuala Lumpur

Malaysia

yasmin_alambina@um.edu.my

*Corresponding Author email: a.farhana19@yahoo.com

Submission: 20 November 2020 Revised: 24 December 2020

Accepted: 19 January 2021

Peer-review under responsibility of 6th Asia International Conference 2020 (Online) Scientific Committee http://connectingasia.org/scientific-committee/

(c) 2021 Published by Readers Insight Publisher,

Office \# 6, First Floor, A \& K Plaza, Near D Watson, F-70 Markaz, Islamabad. Pakistan,

editor@readersinsight.net

This is an open access article under the CC BY license (http://creativecommons.org/licenses/4.0/). 


\section{A B S T R A C T}

Effective maintenance management requires proper data management for decision-making purposes. Big Data (BD) and Business Intelligence's (BI) growing trend has created many challenges for government data management in particular. The government finds difficulties in integrating the massive volume of data with high-speed processing due to incapable database management in the current system, and the issues are not appropriately addressed. This paper contributes significantly, which focuses on an intelligent system that lets the government make an integral part of decisionmaking and can be applied horizontally to solve the problems in practice. Accordingly, an efficient data repository system with real-time analysis is proposed in this paper and it looks at a real case study highlighting the need for proper data management in government.

Keywords: Data Management, Big Data, Business Intelligence

\section{R E S E AR C H H I G H L I G T S}

The focus of this study is illustrated by the use of BD and BI, with maintenance management as the key domain. It is noticed that the existing conventional database system unable to process a large amount of big data and current system employ makes it tough for decision making stage as there is lacking of maintenance data in the process (Tretten \& Karim, 2014). This study aims to explore the significance of BD and BI deployments in maintenance management, especially in government office buildings in Putrajaya, using the Microsoft Power Business Intelligence (MS-Power BI). This is a relatively new concept, mainly in the context of maintenance management. It was discovered during the system analysis that the system is a stand-alone and semi-automated. This study offers insight into the usefulness of the idea of BD and BI concept in maintenance management and accelerates the introduction of fourth industrial revolution (Industry 4.0).

\section{GRAPHICALABSTRACT}

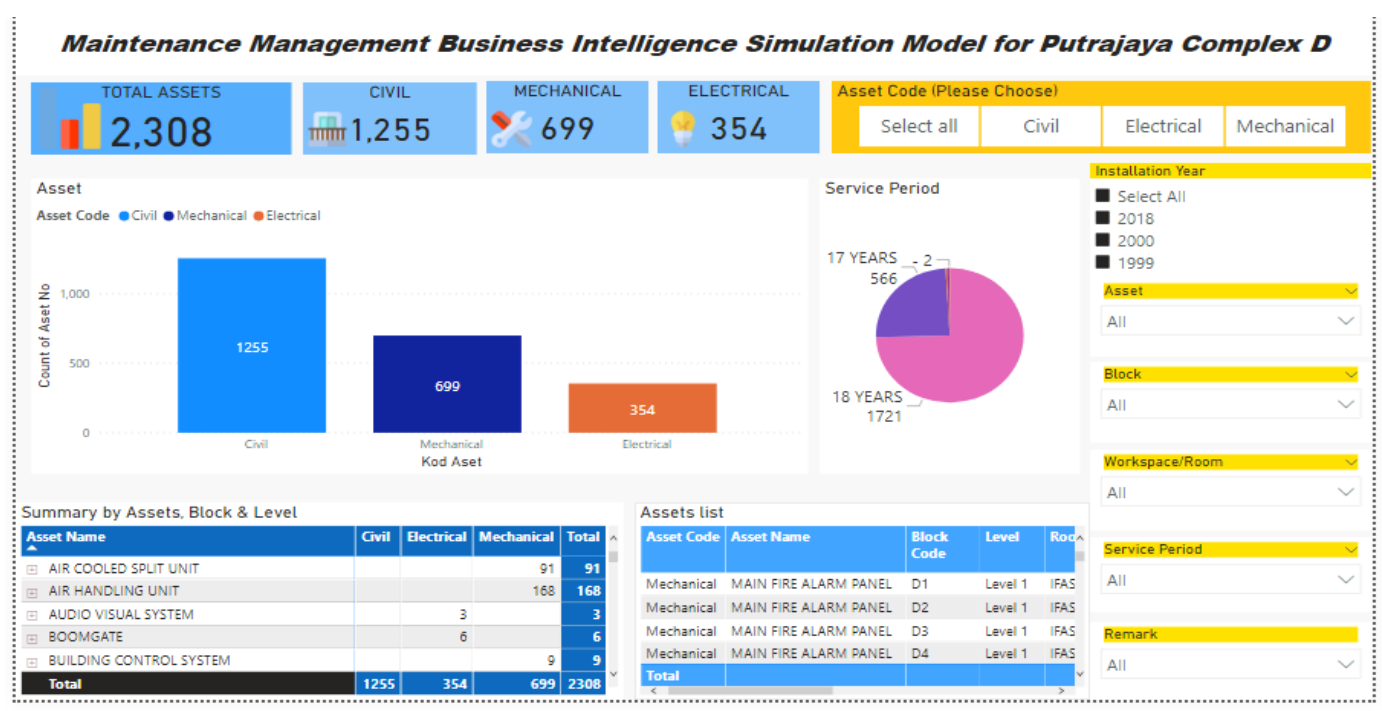

Fig. 1. Maintenance Management Simulation Model through MS-Power BI in Government Office Building 


\section{Research Objectives}

Maintenance management deals with enormous quantities of daily data generated, and the management system is often autonomous and distinct from each other. In order to monitor building maintenance management, it is crucial to establish effective data management system. In Malaysia, the accountability of managing maintenance work for the government asset in Putrajaya is categorised under Public Work Department jurisdiction and also known as Jabatan Kerja Raya Wilayah Persekutuan (JKRWPP), in which a qualified contractor has been appointed to do such work. With the increase in technology inserted in the government maintenance practice, it creates a challenge to manage the substantial amount of data because there has been little focus on data management adoption in the local government context. The use of traditional database system would not be a better solution. By finding insight on this loT, the government can make use wisely in managing the data, particularly in maintenance for office buildings in Putrajaya. The execution of $\mathrm{BI}$ and $\mathrm{BD}$ seems to be crucial as it offers new users with friendly and intuitive data processing, such as Microsoft Power BI and Tableau (www.tableau.com) for data analysis purposes in government sector, thus, improving data management for government sector in maintenance management.

\section{Methodology}

This paper attempts to achieve: 1) existing big data and business intelligence adoption in government office building particularly in Putrajaya, as well as 2) maintenance of management business intelligence simulation model for maintenance activities in government office buildings of Putrajaya. First objective is accomplished by means of a statistical data analysis technique for measuring the frequency distribution (Haneem et al., 2017). The next process was to translate the big data concept for maintenance management in government building through MS-Power Bl in achieving second objective. The process involves data processing using MS-Power BI. The steps taken to process the data on MS-Power BI were as follows: 1) open my workspace data set, then select the imported data in Excel spreadsheet, 2) select the type of graphic that the users want to display, 3) specify the fields that will be the source values for the axes and values, 4) set the desired display of information based on the user needs; for example, filter the top or bottom 10 values, screen them, and display the average value or amount, as well as 5) create a dashboard display based on the desired information.

\section{Results}

Reflecting on our focus on the government sector, we first conducted a questionnaire survey which involved respondents from Facilities Management (FM) contractors in Putrajaya government office building for first objective. The questionnaire consists of Section A related to general questions about the experts' background, Section B focused on current practice of maintenance management in government buildings, and Section $\mathrm{C}$ was narrowed to big data and business intelligence in maintenance management. The result from the questionnaire survey is used as a guide to develop maintenance 
management simulation model in government building through MS-Power BI. While, the results for second objective through MS-Power $\mathrm{Bl}$ depicts full maintenance data in Complex D inclusive of civil, mechanical and electrical work (Figure 1). In Power BI, all data could be viewed using a dashboard that would enable the users to view in 'focus mode' and interactive. The dashboard reports provide the users the ability to filter the data based on location and current status, giving a visible representation of how assets are allocated across the organisation. Through the maintenance management simulation model, a single data can accumulate with other data to create useful information, especially in decision-making process.

\section{Findings}

The proposed paper analysis emphasises on the BD and BI integration to perform data analytics on the basis of case studies performed at the government office buildings at Complex D in Putrajaya. MS-Power BI as an analytics tool provides a user-friendly and interactive interface enabling the extraction of information to be made using the distinctive tools for data visualisation. From the maintenance management simulation model, a well-executed data management is a crucial piece, making the government more agile and most importantly, reduce the risks of losing important information in Public Work Department (Dutta, 2019)

\section{References}

Dutta, P. (2019). Business Analytics using Microsoft Power BI and AWS Redshift. International Journal of Trend in Scientific Research and Development, Volume3(Issue-2), 984-986. https://doi.org/10.31142/ijtsrd21545

Haneem, F., Ali, R., Kama, N., \& Basri, S. (2017). Descriptive analysis and text analysis in Systematic Literature Review: A review of Master Data Management. International Conference on Research and Innovation in Information Systems, ICRIIS, October. https://doi.org/10.1109/ICRIIS.2017.8002473

Tretten, P., \& Karim, R. (2014). Enhancing the usability of maintenance data management systems. Journal of Quality in Maintenance Engineering, 20(3), 290-303. https://doi.org/10.1108/JQME-05-2014-0032

\section{Author's Biography}

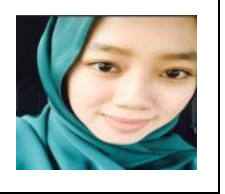

Ain Farhana Jamaludin is currently a PhD student working on big data and business intelligence implementation in maintenance management particularly in government office buildings of Putrajaya, Malaysia 